\title{
Associations of physical partner violence and sexual violence victimization on health risk behaviours and mental health among university students from 25 countries
}

\author{
Supa Pengpid ${ }^{1,2}$ and Karl Peltzer ${ }^{3^{*}}$ (D)
}

\begin{abstract}
Background: The study aimed to investigate the associations between physical partner violence victimization (IPV) and/or sexual violence victimization and various health risk behaviours and mental health in university students in 25 countries.

Methods: Using a cross-sectional study design, 18,335 university students with a median age of 20 years from 25 countries in Africa, the Americas and Asia, replied to self-reported measures of interpersonal violence, health compromising behaviours, mental health measures and protective factors.

Results: In adjusted logistic regression analysis, physical IPV and/or sexual violence victimization was associated, among men and/or among women, with sexual risk behaviours (multiple sexual partners, alcohol use in the context of sex, diagnosed with HIV and pregnancy), violence related behaviour (in a physical fight and carrying a weapon), poor mental health (depression, loneliness, post-traumatic stress disorder, sleeping problem and short sleep), addictive behaviour (binge drinking, tobacco and drug use), and other health risk behaviour (skipping breakfast and frequent salt intake).
\end{abstract}

Conclusions: We found evidence that physical IPV and/or sexual violence victimization among female and/or male university students was associated with 4 of 5 sexual risk behaviours, 2 violence related behaviours, 5 of 5 poor mental health indicators, 3 of 3 addictive behaviours and 2 of 7 other health risk behaviours.

Keywords: Physical partner violence victimization, Sexual violence victimization, Risk behaviour, Mental health, University students, Multi-country

\section{Background}

Intimate partner violence (IPV) and other violence among adolescents and emerging adults is being increasingly recognized as common and having a wide range of health, behavioural and well-being consequences [1]. Various studies have identified that a history physical

\footnotetext{
* Correspondence: kfpeltzer@gmail.com

${ }^{3}$ Department of Psychology, University of the Free State, Bloemfontein, South Africa

Full list of author information is available at the end of the article
}

IPV and/or sexual violence victimization among male and/or female adolescents or emerging adults is associated with sexual risk behaviours, violence related behaviours, poor mental health, substance use, other health risk behaviours, poor health status and poor academic performance. Sexual risk behaviour among adolescents and emerging adults may include, multiple sexual partners [2-4], unprotected sex [5-9], pregnancy [4-7, 10], and sexually transmitted infections including HIV [5, $10-13]$.

C C The Author(s). 2020 Open Access This article is licensed under a Creative Commons Attribution 4.0 International License, which permits use, sharing, adaptation, distribution and reproduction in any medium or format, as long as you give appropriate credit to the original author(s) and the source, provide a link to the Creative Commons licence, and indicate if changes were made. The images or other third party material in this article are included in the article's Creative Commons licence, unless indicated otherwise in a credit line to the material. If material is not included in the article's Creative Commons licence and your intended use is not permitted by statutory regulation or exceeds the permitted use, you will need to obtain permission directly from the copyright holder. To view a copy of this licence, visit http://creativecommons.org/licenses/by/4.0/ The Creative Commons Public Domain Dedication waiver (http://creativecommons.org/publicdomain/zero/1.0/) applies to the data made available in this article, unless otherwise stated in a credit line to the data. 
Violence-related behaviours among adolescents and emerging adults may include in a physical fight [2, 14], carried a weapon [2], handgun access [15], and injury [5, 10]. Poor mental health as a consequence of physical IPV and/or sexual violence victimization among adolescents and emerging adults may include depression [5, 9, $11,12,16-20]$, posttraumatic stress $[5,11,12,16]$, anxiety $[5,9,16,19]$, psychological distress $[8,21]$, suicidal behaviour $[2,14,17,20]$, sleep disorders $[5,12,13]$, and disordered eating $[5,10]$. Several studies found that a history of physical IPV and/or sexual violence victimization among adolescents and emerging adults increased the odds for substance use, such as alcohol use or binge drinking $[2,5,9,10,13]$, tobacco use $[5,6]$, drug use $[2,5,6,9,10,14]$, and substance use at last sex [3]. Other health risk behaviours include physical inactivity [5], eating unhealthy foods [15], such as inadequate fruit and vegetable intake [22], and not wearing a seatbelt [15]. Moreover, some studies found as a consequence of physical IPV and/or sexual violence victimization a poor self-rated health status [21, 23], poor quality of life [19], and poorer educational outcomes $[9,20]$.

Most studies reviewed above investigated associations between physical IPV and/or sexual violence victimization with single or a few negative outcomes. However, there is a lack of studies examining multiple outcomes, such as sexual risk behaviours, violence related behaviours, poor mental health, substance use, other health risk behaviours, poor health status and poor academic performance in the same study population. In particular, information is scarce on multiple consequences of physical IPV and/or sexual violence victimization in university students in low- and middle-income countries. "While there has been much empirical research on adult dating violence, only recently has research began to also focus on young adult dating violence in general." [24] Therefore, the study aimed to assess the associations of physical IPV and/or sexual violence victimization with various health risk indicators and mental health among university students in 25 countries in the Americas, Africa and Asia.

\section{Methods}

\section{Sample and procedure}

The cross-sectional study comprised 18,335 college or university students with a median age of 20 years (interquartile range $=3$ years) with complete physical IPV and/ or sexual violence victimization data from 25 countries in Southeast Asia: Indonesia, Laos, Philippines, Singapore and Thailand; South Asia and China: India, Pakistan and China; North Africa and Central Asia: Egypt, Tunisia, Turkey, Russia and Kyrgyzstan; the Americas: Barbados, Columbia, Grenada, Jamaica and Venezuela and in subSaharan Africa: Cameroon, Ivory Coast, Madagascar,
Mauritius, Namibia, Nigeria and South Africa. The study was initiated through personal, academic contacts of the principal investigators; thus, in each study country one or two universities were purposefully selected, [25] targeting 400 male and 400 female undergraduate university students aged 16-30 years. "The participants were identified using a quasi-random selection process, which entailed randomly selecting one department from each University faculty, and a random selection was then made from an ordered list of all undergraduate courses offered within the selected department" [25] "Trained research assistants then described the study to students within the selected undergraduate class to recruit participants. The inclusion criterion was being present in class at the time of recruitment." [25]. The consent form included a written justification of the study and contact details of the local principal investigator were provided in order to respond to any questions or personal concerns. Trained research assistants administered the paper-based self-administered questionnaire and made sure that each student had privacy when filling in the questionnaire. The consent forms and the questionnaires (without identifying information) were collected separately and placed in different boxes in the front of the rooms. "Informed consent was attained from all participating students, and ethics approvals were obtained from all participating universities. Participation rates were in most countries over 90\%" [26].

"For the population survey, the expected frequency of $50 \%$ (maximum possible percentage of students with positive and negative health behaviors), design effect 1 (in calculation used given the ratio of the actual variance, under the sampling method, to the variance computed under the assumption of simple random sampling), confidence limited $5 \%$, cluster 1 , form this confidence limited 5\% key in to calculating formula, will get outcome of sample size calculated for seven confidence levels, the researchers chose sample size for confidence of $99 \%$, the minimum sample size is 663 .To prevent incomplete data, the sample size was increased to 800 (400 male, 400 female)." [27].

\section{Measures}

Physical IPV and sexual violence victimization were sourced from two questions: "1) Have you ever been hit by a sexual partner? and 2) Have you ever been forced to have sex?" (yes, no) [28].

Socio-demographic information comprised gender, age, subjective wealth status and country income.

Social support was sourced from three questions of the "Social Support Questionnaire" [29] (Cronbach's alpha 0.94).

Physical childhood abuse was assessed with item: "Have you ever been physically abused as a child" (yes, no) [30]. 
Sexual risk behaviour included "two or more sexual partners in the past 12 months", "alcohol use in the context of sex in the past 3 months", "history of having been diagnosed with a sexually transmitted infection (STI)", "diagnosed with HIV" and "ever made someone pregnant/been pregnant" [31].

\section{Violence related behaviour}

Having been in a physical fight was defined as "having been involved in a physical fight one or more times in the past 12 months" [32].

Weapon carrying was defined as "carrying a weapon such as a gun, knife, or club" on one or more days in the past month [33].

Injury was defined as "serious injury when it makes you miss at least one full day of usual activities (such as college, sports, studies or a job) or requires treatment by a doctor or nurse" in the past 12 month [32].

\section{Mental health}

The "Centres for Epidemiologic Studies Depression Scale (CES-D-10)" measured with 15 or more scores severe depressive symptoms [34]. (Cronbach's alpha $=0.76$ ).

Loneliness was defined as most (5-7 days) feeling lonely in the past week [34].

"Post-traumatic stress disorder (PTSD)" was measured with "Breslau's 7-item screener" [35].

Sleeping problem was defined as "an extreme/cannot do problem with sleeping, such as falling asleep, waking up frequently during the night, or waking up too early in the morning." [36].

Sleep duration: "On average, how many hours of sleep do you get in a $24 \mathrm{~h}$ period?" "Responses were divided into three categories: short sleep $(\leq 6 \mathrm{~h})$, reference category $(7-8 \mathrm{~h})$, and long sleep $(\geq 9 \mathrm{~h})$ " [37].

\section{Addictive behaviour}

Binge drinking (past-month) was assessed with the item, "How often do you have (for men) five or more and (for women) four or more drinks on one occasion?" [38].

Tobacco use was defined as currently using "tobacco products (cigarettes, snuff, chewing tobacco, cigars, etc.)" [39].

Illicit drug use was defined as " 10 or more times having taken any drugs other than those prescribed by health care providers in the past 12 months." [40]

\section{Other health risk behaviour}

Physical activity was measured using the "International Physical Activity Questionnaire (IPAQ) short form" [41], and physical activity levels were defined following IPAQ guidelines [42].

Breakfast consumption was measured with the item, "How often do you eat breakfast?" ("Almost every day, sometimes, rarely or never") [43]. Skipping breakfast was defined as sometimes, rarely or never having breakfast.

Fruit and vegetable intake was measured with two questions, 1) "How many servings [80 grams] of fruit do you eat on a typical day?" and 2) "How many servings [80 g] of vegetables do you eat on a typical day?” [44]. Inadequate fruit and vegetable intake was defined as "less than 5 servings a day" [45].

Adding salt to food was defined as usually adding salt to food (options: "usually, sometimes, occasionally, never") [43].

Seatbelt use was measured with the item, "When driving or riding in the front seat of a car do you wear a seat belt?" (" $1=$ all of the time, $2=$ some of the time, $3=$ never and $4=$ I don't ride in cars") [43].

Self-rated health status was assessed by a single item, "In general, would you say that your health is ... Excellent, Very good, Good, Fair or Poor" [43].

Poor academic performance was self-reported as "not satisfactory academic performance." [46].

\section{Data analysis}

Data analysis was conducted with "STATA software version 15.0 (Stata Corporation, College Station, TX, USA)". Unadjusted and multivariable (adjusted for relevant confounders age, study year, subjective economic status, country, social support, and exposure to physical and/or sexual violence in childhood) logistic regression was used to assess the associations between physical and/or sexual IPV victimization and dependent variables ( 5 sexual risk behaviours, 3 violence related behaviours, 5 poor mental health indicators, 3 addictive behaviours, 5 other health risk behaviours, and academic performance). Due to the clustered nature of the data, country was entered in the survey command. Missing data $(<8 \%$ on any variable) were excluded from the analysis. $P$ values $<0.05$ were considered significant.

\section{Results \\ Descriptive results}

The sample consisted of 18,335 university students (median age 20 years, interquartile range 3 years) from 25 countries, $59.0 \%$ were females and $41.0 \%$ males, $52.6 \%$ rated their economic status as high, $57.3 \%$ had high social support, $46.0 \%$ were residing in low- or lower middle-income countries. A history of child physical abuse was reported by 4.8 , and $8.0 \%$ had been exposed to physical IPV and/or sexual violence victimization.

In terms of sexual risk behaviour, 19.2\% of students reported to have had multiple sexual partners in the past 12 months, $14.1 \%$ had used alcohol in the context of sex, $5.7 \%$ had a history of a sexually transmitted infection, $0.6 \%$ had been diagnosed with HIV and $8.1 \%$ had been or made someone pregnant. Regarding violence related 
behaviour, $12.7 \%$ of students had been involved in physical fighting in the past year, $6.0 \%$ had carried a weapon in th past 30 days, and $24.5 \%$ had sustained a serious injury in the past year. Mental health indicators showed that $13.0 \%$ of students had depression symptoms, 10.3\% loneliness, 19.7\% PTSD, 10.2\% sleeping problems and $39.7 \%$ short sleep. In terms of addictive behaviour, $12.5 \%$ of students were current binge drinkers, $12.4 \%$ current tobacco users and $3.7 \%$ frequent drug users. Regarding other health risk behaviours, $42.2 \%$ of students were physically inactive, $46.6 \%$ skipped breakfast, $81.3 \%$ had inadequate fruit and vegetable intake, $40.0 \%$ had salt usually and $53.9 \%$ had not always been a seatbelt. Almost one in ten students $(8.8 \%)$ rated their health status as poor, and $6.1 \%$ rated their academic performance as poor.

\section{Associations between physical IPV and/or sexual violence victimization and outcome variables}

In adjusted logistic regression analyses among both sexes, physical IPV and/or sexual violence victimization was associated with sexual risk behaviour (having had multiple sexual partners, alcohol use in the context of sex, diagnosed with HIV and pregnancy), violence related behaviour (been in a physical fight and carried a weapon). Regarding poor mental health, among women physical IPV and/or sexual violence victimization was associated depression, lonelinss, PTSD, sleeping problem and short sleep, while among men only PTSD and sleeping problem were associated. In terms of addictive behaviour, among both sexes physical IPV and/or sexual violence victimization was associated with tobacco use, while among men with drug use and among women with binge drinking. Among men tobacco and drug use was associated. Moreover, among both sexes, physical IPV and/or sexual violence victimization was associated with skipping breakfast and frequent salt intake (see Table 1).

\section{Associations of physical IPV and/or sexual violence victimization with risk behaviours by region}

Dividing our study population into five regions (Americas, sub-Saharan Africa, North Africa and Central Asia, South Asia and China and Southeast Asia), results show that physical IPV and/or sexual violence victimization was associated with multiple sexual partners and pregnancy in three regions (Americas, sub-Saharan Africa and South Asia and China, and Americas, subSaharan Africa and North Africa and Central Asia, respectively). Further, physical IPV and/or sexual violence victimization was associated with alcohol use in the context of sex and weapon carrying in four regions (sub-Saharan Africa, North Africa \& Central Asia, South Asia and China and Southeast Asia). Associations with involvement in physical fighting was found in two regions (sub-Saharan Africa and North Africa \& Central Asia). An association with skipping breakfast was only found in the sub-Saharan African region, and a positive association with salt intake was found in the Americas and a negative association with salt intake in South Asia and China (see Table 2).

\section{Associations of physical IPV and/or sexual violence victimization with mental health and substance use by region}

Physical IPV and/or sexual violence victimization was associated with current binge drinking and current tobacco use in all five study regions. Associations with PTSD and sleeping problem were found in all five regions except for North Africa and Central Asia for PTSD and Southeast Asia for sleeping problem. Associations with depression were found for two regions (Americas and sub-Saharan Africa) and associtions with short sleep were found for th Americas and South Asia and China. Finally an association with loneliness was only found in students from sub-Saharan Africa and with drug use in students from Southeast Asia (see Table 3).

\section{Discussion}

Consistent with findings of various previous studies [2$5,10-12]$, this study found among men and women that physical IPV and/or sexual violence victimization was associated with sexual risk behaviour (having had multiple sexual partners, alcohol use in the context of sex, diagnosed with HIV and pregnancy), and violence related behaviour (been in a physical fight and carried a weapon). In agreement with previous findings $[2,5,6,8-13,16-$ 20], physical IPV and/or sexual violence victimization was overall and among women associated with all 5 mental health indicators (depression, loneliness, PTSD, sleeping problem and short sleep) and among men 2 poor mental health indicators (PTSD and sleeping problem), and overall victimization was associated with 3 addictive behaviours (alcohol, tobacco and drug use), among women 2 addictive behaviours (binge drinking and tobacco use) and among men 2 addictive behaviours (tobacco use and drug use).

The study also found some evidence that physical IPV and/or sexual violence victimization was associated other health risk behaviours, such as an unhealthy diet (skipping breakfast and frequent salt intake), as found in a previous study [15]. Contrary to some previous investigations $[5,15,19-23]$, this study did not find an association between physical IPV and/or sexual violence victimization and physical inactivity, inadequate fruit and vegetable intake, not always wearing a seatbelt, poor self-rated health status, and poorer educational outcomes. In addition, some studies found an association 
Table 1 Associations of physical IPV and/or sexual victimization on risk behaviours and mental health

\begin{tabular}{|c|c|c|c|c|}
\hline \multirow[t]{2}{*}{ Variable (prevalence) } & & \multirow{2}{*}{$\begin{array}{l}\text { All } \\
\text { OR (95\% Cl) }\end{array}$} & \multirow{2}{*}{$\begin{array}{l}\text { Male } \\
\text { OR (95\% Cl) }\end{array}$} & \multirow{2}{*}{$\begin{array}{l}\text { Female } \\
\text { OR (95\% Cl) }\end{array}$} \\
\hline & & & & \\
\hline \multicolumn{5}{|l|}{ Sexual risk behaviour } \\
\hline \multirow[t]{2}{*}{ Two or more sexual partners in past year (19.2\%) } & UOR & $3.65(1.90,7.02)^{* * *}$ & $3.41(2.01,5.77)^{* * *}$ & $4.08(1.54,10.85)^{* * *}$ \\
\hline & $\mathrm{AOR}^{\mathrm{a}}$ & $3.81(2.28,6.36)^{* * *}$ & $3.74(2.40,5.83)^{* * *}$ & $4.11(2.05,8.22)^{* * *}$ \\
\hline \multirow[t]{2}{*}{ Alcohol use in the context of sex (14.1\%) } & UOR & $3.26(2.16,4.93)^{* * *}$ & $2.74(1.74,4.30)^{* * *}$ & $4.00(2.50,6.38)^{* * *}$ \\
\hline & $A O R^{a}$ & $3.14(2.14,4.60)^{* * *}$ & $3.01(2.05,4.40)^{* * *}$ & $3.21(2.00,5.18)^{* * *}$ \\
\hline History of sexually transmitted infection (5.7\%) & UOR & $1.90(0.58,6.19)$ & $1.89(0.67,5.31)$ & $1.92(0.52,7.01)$ \\
\hline \multirow[t]{2}{*}{ Diagnosed with HIV (0.6\%) } & UOR & $23.08(11.69,46.34)^{* * *}$ & $28.04(11.33,71.62)^{* * *}$ & $19.04(9.72,37.03)^{* * *}$ \\
\hline & $A O R^{a}$ & $11.43(5.73,22.82)^{* * *}$ & $15.73(6.96,33.51)^{* * *}$ & $8.87(3.99,19.72)^{* * *}$ \\
\hline \multirow[t]{2}{*}{ Pregnancy (8.1\%) } & UOR & $5.74(4.01,8.21)^{* * *}$ & $3.63(2.79,5.76)^{* * *}$ & $8.25(5.09,13.37)^{* * *}$ \\
\hline & $\mathrm{AOR}^{\mathrm{a}}$ & $5.49(3.92,7.70)^{* * *}$ & $3.50(2.38,5.13)^{* * *}$ & $8.13(4.90,13.49)^{* * *}$ \\
\hline \multicolumn{5}{|l|}{ Violence related behaviour } \\
\hline \multirow[t]{2}{*}{ Was in a physical fight in the past 12 month (12.7\%) } & UOR & $3.14(2.16,4.56)^{* * *}$ & $3.22(2.17,5.76)^{* * *}$ & $2.87(2.03,4.06)^{* * *}$ \\
\hline & $A O R^{a}$ & $2.52(1.68,3.77)^{* * *}$ & $2.85(1.97,4.13)^{* * *}$ & $1.97(1.38,2.81)^{* * *}$ \\
\hline \multirow[t]{2}{*}{ Weapon carrying in the past 30 days (6.0\%) } & UOR & $2.57(1.85,3.56)^{* * *}$ & $2.56(1.80,3.65)^{* * *}$ & $2.29(1.66,3.18)^{* * *}$ \\
\hline & $\mathrm{AOR}^{\mathrm{a}}$ & $2.14(1.64,2.78)^{* * *}$ & $2.34(1.77,3.09)^{* * *}$ & $1.72(1.23,2.43)^{* *}$ \\
\hline Injury in the past year (24.5\%) & UOR & $1.28(0.96,1.72)$ & $1.29(0.91,1.83)$ & $1.20(0.86,1.69)$ \\
\hline \multicolumn{5}{|l|}{ Mental health } \\
\hline \multirow[t]{2}{*}{ Depression severe (13.0\%) } & UOR & $1.92(1.50,2.45)^{* * *}$ & $1.46(1.04,2.03)^{*}$ & $2.35(1.75,3.15)^{* * *}$ \\
\hline & $A O R^{b}$ & $1.40(1.13,1.74)^{* *}$ & $1.16(0.86,1.56)$ & $1.63(1.18,2.25)^{* *}$ \\
\hline \multirow[t]{2}{*}{ Loneliness (10.3\%) } & UOR & $1.62(1.20,2.19)^{* *}$ & $1.25(0.78,2.01)$ & $1.97(1.35,2.87)^{* * *}$ \\
\hline & $\mathrm{AOR}^{\mathrm{c}}$ & $1.41(1.06,1.86)^{*}$ & $1.12(0.721 .74)$ & $1.69(1.13,2.13)^{* *}$ \\
\hline \multirow[t]{2}{*}{ Post-traumatic stress disorder (19.7\%) } & UOR & $2.47(1.90,3.22)^{* * *}$ & $1.97(1.47,2.64)^{* * *}$ & $2.99(2.21,4.03)^{* * *}$ \\
\hline & $A O R^{d}$ & $1.92(1.52,2.42)^{* * *}$ & $1.66(1.30,2.13)^{* * *}$ & $2.18(1.57,3.02)^{* * *}$ \\
\hline \multirow[t]{2}{*}{ Sleeping problem (10.2\%) } & UOR & $1.83(1.40,2.39)^{* * *}$ & $1.90(1.35,2.68)^{* * *}$ & $1.79(1.26,2.55)^{* *}$ \\
\hline & $\mathrm{AOR}^{\mathrm{c}}$ & $1.71(1.34,219)^{* * *}$ & $1.80(1.31,2.49)^{* * *}$ & $1.65(1.16,2.33)^{* *}$ \\
\hline \multirow[t]{2}{*}{ Short sleep (39.7\%) } & UOR & $1.33(1.09,1.62)^{* *}$ & $1.26(1.00,1.59)^{*}$ & $1.38(1.08,1.75)^{*}$ \\
\hline & $\mathrm{AOR}^{\mathrm{C}}$ & $1.28(1.03,1.58)^{*}$ & $1.19(0.92,1.54)$ & $1.35(1.06,1.71)^{*}$ \\
\hline \multicolumn{5}{|l|}{ Addictive behaviour } \\
\hline \multirow[t]{2}{*}{ Current binge drinking (12.5\%) } & UOR & $1.91(1.28,2.84)^{* *}$ & $1.38(0.82,2.32)$ & $2.61(1.82,3.75)^{* *}$ \\
\hline & $A_{O R}{ }^{e}$ & $1.88(1.34,2.64)^{* * *}$ & $1.38(0.87,2.19)$ & $2.56(1.84,3.55)^{* * *}$ \\
\hline \multirow[t]{2}{*}{ Current tobacco use (12.4\%) } & UOR & $3.13(2.12,4.63)^{* * *}$ & $2.92(2.01,4.23)^{* *}$ & $3.34(2.22,5.04)^{* * *}$ \\
\hline & $\mathrm{AOR}^{\mathrm{a}}$ & $2.57(1.75,3.77)^{* * *}$ & $2.60(1.84,3.67)^{* * *}$ & $2.45(1.70,3.54)^{* * *}$ \\
\hline \multirow[t]{2}{*}{ Drug use (10 or more times in past 12 months) (3.7\%) } & UOR & $2.04(1.27,3.26)^{* *}$ & $1.98(1.01,3.90)^{*}$ & $2.04(1.02,4.09)^{*}$ \\
\hline & $\mathrm{AOR}^{\mathrm{a}}$ & $1.72(1.11,2.67)^{*}$ & $1.80(1.00,3.31)^{*}$ & $1.56(0.81,3.04)$ \\
\hline \multicolumn{5}{|l|}{ Other health risk behaviour } \\
\hline Physical inactivity (42.2\%) & UOR & $0.81(0.56,1.18)$ & $0.83(0.58,1.20)$ & $0.84(0.55,1.29)$ \\
\hline \multirow[t]{2}{*}{ Skipping breakfast (46.6\%) } & UOR & $1.33(1.12,1.58)^{* *}$ & $1.42(1.18,1.71)^{* * *}$ & $1.27(0.98,1.64)$ \\
\hline & $A O R^{a}$ & $1.20(1.04,1.40)^{*}$ & $1.42(1.19,1.69)^{* * *}$ & $1.06(0.85,1.33$ \\
\hline Inadequate fruit and vegetable intake (81.3\%) & UOR & $0.91(0.71,1.18)$ & $0.79(0.64,0.98)^{*}$ & $1.05(0.70,1.58)$ \\
\hline Salt usually (40.0\%) & UOR & $1.44(1.04,2.00)^{*}$ & $1.43(0.99,2.07)$ & $1.47(1.05,2.05)^{*}$ \\
\hline & $\mathrm{AOR}^{\mathrm{a}}$ & $1.46(1.14,1.88)^{* *}$ & $1.43(1.05,1.93)^{*}$ & $1.53(1.19,1.98)^{* *}$ \\
\hline Not always wearing a seatbelt (53.9\%) & UOR & $0.88(0.63,1.24)$ & $0.88(0.60,1.30)$ & $0.88(0.59,1.29)$ \\
\hline Subjective health (poor) (8.8\%) & UOR & $1.42(0.89,2.28)$ & $1.56(0.94,2.68)$ & $1.07(0.71,1.60)$ \\
\hline Academic performance (poor) $(6.1 \%)$ & UOR & $0.97(0.69,1.35)$ & $0.96(0.68,1.34)$ & $0.92(0.54,1.57)$ \\
\hline
\end{tabular}

UOR unadjusted odds ratio, $A O R$ adjusted odds ratio; ${ }^{* * *} P<0.001 ;{ }^{*} P<0.01 ;{ }^{*} P<0.05 ;{ }^{a}$ Model 1 : Adjusted for age, sex, study year, social support, family income or wealth, country, exposure to physical violence in childhood, binge drinking, depression and PTSD; ${ }^{\mathrm{b}}$ Adjusted for all variables in model 1, except for depression; ${ }^{\mathrm{c}}$ Adjusted for all variales in model 1, expect for depression and PTSD; ${ }^{\mathrm{d}}$ Adjusted for all variales in model 1, except for PTSD; ${ }^{\mathrm{A}}$ Adjusted for all variables in model 1 , except for binge drinking 
Table 2 Associations of physical IPV and/or sexual victimization with risk behaviours by region

\begin{tabular}{|c|c|c|}
\hline Variable & Region (prevalence of outcome variable) & $\operatorname{AOR}^{a}(95 \% C l)$ \\
\hline \multicolumn{3}{|l|}{ Risk behaviour } \\
\hline \multirow[t]{5}{*}{ Two or more sexual partners in past year } & Americas (26.1\%) & $2.21(1.46,3.36)^{* * *}$ \\
\hline & Sub-Saharan Africa (24.2\%) & $3.21(2.47,4.19)^{* * *}$ \\
\hline & North Africa \& Central Asia (36.8\%) & $2.32(0.89,6.04)$ \\
\hline & South Asia and China (1.5\%) & $12.86(4.29,38.54)^{* * *}$ \\
\hline & Southeast Asia (3.5\%) & $2.53(0.50,12.84)$ \\
\hline \multirow[t]{5}{*}{ Alcohol use in the context of sex } & Americas (25.2\%) & $1.60(0.94,2.73)$ \\
\hline & Sub-Saharan Africa (14.1\%) & $2.62(1.63,4.23)^{* * *}$ \\
\hline & North Africa \& Central Asia (9.9\%) & $4.38(3.37,5.70)^{* * *}$ \\
\hline & South Asia and China (2.0\%) & $24.92(2.75,225.53)^{* *}$ \\
\hline & Southeast Asia (9.7\%) & $4.68(1.61,13.60)^{* *}$ \\
\hline \multirow[t]{5}{*}{ Pregnancy } & Americas (12.4\%) & $3.51(2.42,5.10)^{* * *}$ \\
\hline & Sub-Saharan Africa (16.2\%) & $3.34(2.16,5.18)^{* * *}$ \\
\hline & North Africa \& Central Asia (5.0\%) & $7.95(4.04,8.76)^{* * *}$ \\
\hline & South Asia and China (1.8\%) & $5.28(0.81,4.10)$ \\
\hline & Southeast Asia (2.8\%) & $2.84(0.71,11.44)$ \\
\hline \multirow[t]{5}{*}{ Was in a physical fight in the past 12 month } & Americas (10.7\%) & $1.36(0.94,1.99)$ \\
\hline & Sub-Saharan Africa (14.4\%) & $2.12(1.26,2.58)^{* *}$ \\
\hline & North Africa \& Central Asia (18.3\%) & $3.49(2.72,4.46)^{* * *}$ \\
\hline & South Asia and China (12.1\%) & $1.97(0.93,4.19)$ \\
\hline & Southeast Asia (7.2\%) & $3.17(0.96,10.37)$ \\
\hline \multirow[t]{5}{*}{ Weapon carrying in the past 30 days } & Americas (6.2\%) & $1.39(0.95,2.02)$ \\
\hline & Sub-Saharan Africa (5.7\%) & $2.10(1.51,2.93)^{* * *}$ \\
\hline & North Africa \& Central Asia (9.1\%) & $2.14(1.56,2.95)^{* * *}$ \\
\hline & South Asia and China (5.1\%) & $2.49(1.50,4.13)^{* * *}$ \\
\hline & Southeast Asia (3.5\%) & $5.31(3.86,7.28)^{* * *}$ \\
\hline \multirow[t]{5}{*}{ Skipping breakfast } & Americas (43.8\%) & $1.44(0.98,2.10)$ \\
\hline & Sub-Saharan Africa (49.9\%) & $1.21(1.01,1.44)^{*}$ \\
\hline & North Africa \& Central Asia (45.9\%) & $1.13(0.84,1.51)$ \\
\hline & South Asia and China (37.2\%) & $1.29(0.77,2.16)$ \\
\hline & Southeast Asia (51.9\%) & $1.06(0.62,1.83)$ \\
\hline \multirow[t]{5}{*}{ Salt usually } & Americas (27.3\%) & $1.33(1.01,1.76)^{*}$ \\
\hline & Sub-Saharan Africa (49.9\%) & $1.26(0.86,1.84)$ \\
\hline & North Africa \& Central Asia (52.9\%) & $1.25(0.90,1.74)$ \\
\hline & South Asia and China (38.4\%) & $0.58(0.32,0.93)^{*}$ \\
\hline & Southeast Asia (27.1\%) & $0.92(0.42,1.99)$ \\
\hline
\end{tabular}

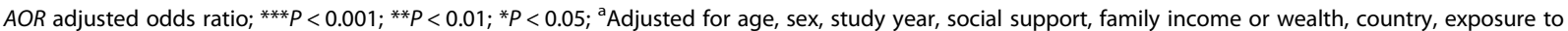
physical violence in childhood, binge drinking (if not outcome variable), depression (if not outcome variable) and PTSD (if not outcome variable)

between physical IPV and injury [5, 10], while this study did not find this association. This may be explained by failing to assess injurious consequences of physical IPV in this study.

Our results demonstrate the wide range of associations between physical IPV and/or sexual violence victimization and multiple outcomes, such as sexual risk behaviours, violence related behaviours, poor mental health, substance use and other health risk behaviours, with similar patterns observed for male and female students as well as across the five study regions. Generally, both men and women responded to victimization with 
Table 3 Associations of physical IPV and/or sexual victimization with mental health and substance use by region

\begin{tabular}{|c|c|c|}
\hline Variable & Region (prevalence of outcome variable) & $\mathrm{AOR}^{\mathrm{a}}(95 \% \mathrm{Cl})$ \\
\hline \multicolumn{3}{|l|}{ Mental health } \\
\hline \multirow[t]{5}{*}{ Depression severe } & Americas (12.8\%) & $2.04(1.63,2.55)^{* * *}$ \\
\hline & Sub-Saharan Africa (12.8\%) & $1.32(1.12,1.55)^{* * *}$ \\
\hline & North Africa \& Central Asia (16.2\%) & $1.06(0.82,1.37)$ \\
\hline & South Asia and China (17.9\%) & $1.45(0.90,2.35)$ \\
\hline & Southeast Asia (6.8\%) & $1.16(0.74,1.83)$ \\
\hline \multirow[t]{5}{*}{ Loneliness } & Americas (10.6\%) & $1.30(0.94,1.80)$ \\
\hline & Sub-Saharan Africa (10.8\%) & $1.52(1.17,1.96)^{* *}$ \\
\hline & North Africa \& Central Asia (12.3\%) & $1.03(0.75,1.41)$ \\
\hline & South Asia and China (12.8\%) & $1.43(0.89,2.30)$ \\
\hline & Southeast Asia (5.1\%) & $1.75(0.55,5.63$ \\
\hline \multirow[t]{5}{*}{ Post-traumatic stress disorder } & Americas (18.3\%) & $2.68(2.00,3.60)^{* * *}$ \\
\hline & Sub-Saharan Africa (20.2\%) & $2.22(2.76,2.80)^{* * *}$ \\
\hline & North Africa \& Central Asia (24.7\%) & $1.32(0.81,2.14)$ \\
\hline & South Asia and China (19.4\%) & $2.73(1.53,4.94)^{* * *}$ \\
\hline & Southeast Asia (16.4\%) & $2.80(2.19,3.57)^{* * *}$ \\
\hline \multirow[t]{5}{*}{ Sleeping problem } & Americas (10.1\%) & $1.58(1.27,1.96)^{* * *}$ \\
\hline & Sub-Saharan Africa (11.1\%) & $1.97(1.58,2.45)^{* * *}$ \\
\hline & North Africa \& Central Asia (9.9\%) & $1.56(1.24,1.97)^{* * *}$ \\
\hline & South Asia and China (8.4\%) & $1.82(11.0,2.99)^{*}$ \\
\hline & Southeast Asia (10.8\%) & $1.06(0.36,3.05)$ \\
\hline \multirow[t]{5}{*}{ Short sleep } & Americas (42.1\%) & $1.34(1.00,1.80)^{*}$ \\
\hline & Sub-Saharan Africa (42.5\%) & $1.05(0.82,1.33)$ \\
\hline & North Africa \& Central Asia (35.8\%) & $1.15(0.75,1.76)$ \\
\hline & South Asia and China (28.9\%) & $2.82(1.18,6.76)^{*}$ \\
\hline & Southeast Asia (45.1\%) & $1.49(0.68,3.28)$ \\
\hline \multicolumn{3}{|l|}{ Addictive behaviour } \\
\hline \multirow[t]{5}{*}{ Current binge drinking } & Americas (27.5\%) & $1.27(1.02,1.59)^{*}$ \\
\hline & Sub-Saharan Africa (11.6\%) & $1.45(1.02,2.07)^{*}$ \\
\hline & North Africa \& Central Asia (10.6\%) & $1.94(1.38,2.71)^{* * *}$ \\
\hline & South Asia and China (2.7\%) & $10.41(9.01,13.54)^{* * *}$ \\
\hline & Southeast Asia (10.6\%) & $2.93(2.05,4.17)^{* * *}$ \\
\hline \multirow[t]{5}{*}{ Current tobacco use } & Americas (10.0\%) & $1.41(1.00,2.00)^{*}$ \\
\hline & Sub-Saharan Africa (12.6\%) & $2.45(1.52,3.97)^{* * *}$ \\
\hline & North Africa \& Central Asia (23.4\%) & $2.87(2.33,3.54)^{* * *}$ \\
\hline & South Asia and China (7.5\%) & $6.88(3.11,15.20)^{* * *}$ \\
\hline & Southeast Asia (6.0\%) & $2.30(1.03,5.16)^{*}$ \\
\hline \multirow[t]{5}{*}{ Drug use (10 or more times in past 12 months) } & Americas (4.4\%) & $0.86(0.51,1.44)$ \\
\hline & Sub-Saharan Africa (7.3\%) & $1.46(0.92,2.31)$ \\
\hline & North Africa \& Central Asia (2.5\%) & $1.99(0.85,4.64)$ \\
\hline & South Asia and China (0.9\%) & $0.88(0.18,4.16)$ \\
\hline & Southeast Asia (4.2\%) & $3.42(2.36,4.96)^{* * *}$ \\
\hline
\end{tabular}


internalizing symptoms (PTSD and sleeping problem) and externalizing symptoms (sexual risk behaviour, violence related behaviour and tobacco use). While some of the sex differences may be explained by women responding more likely than men in terms of internalizing symptoms and men more likely than women with externalizing symptoms [17]. For example, women had significantly more internalizing symptoms in terms of depressive symptoms, loneliness and short sleep, than men, while men had significantly more externalizing symptoms in the case of frequent drug use than women. However, mixed evidence for this was found in the case of substance use, where women in this study more likely than men responded with the externalizing symptoms of binge drinking.

In a stratified analysis by study region, associations of physical IPV and sexual violence victimization with the various significant outcome variables in the global analysis were only significant for the majority of the five study regions in case of four risk behaviours (multiple sexual partners, alcohol use in the context of alcohol use, pregnancy and weapon carrying), while involvement in physical fighting, skipping breakfast and taking salt usually was only significant in one or two study regions. One explanation for the non-significant association in some study regions may be attributed to the low prevalence of the outcome variable in specific study regions, e.g., pregnancy and frequent drug use in the South Asia and China region, and depression and loneliness in the Southeast Asia region.

Some of the mechanisms by which violence victimization leads to various consequences have been suggested. For example, trauma theory suggests that violence victims experience their violence victimization as traumatic leading to post-traumatic stress $[47,48]$. Students experiencing adverse outcomes may appraise victimization as psychologically stress ful, and then use unhealthy coping processes to deal with this demand $[49,50]$. Some of these unhealthy coping behaviours may include substance use, violence related behaviour or sexual risk behaviour.

Primary prevention (stopping physical IPV and sexual violence victimization before occurring) is the preferred intervention to prevent various risk behaviours (sexual, violence, substance use and others) and poor mental health. Primary prevention is likely to reduce victimization and various risk behaviours, including poor mental health [14]. In addition, secondary prevention is indicated in limiting or preventing negative consequences of victimization, in particular by addressing identified health risk behaviours and poor mental health indicators. Therefore, the assessment of frequent health risk behaviours and poor mental health indicators among victims of physical IPV and/or sexual violence and interventions targeting to ameliorate these behaviours and incidators will help in reducing short- and long-term health and social consequences [14]. Programmes targeting the prevention of physical IPV and sexual violence victimization among university students should include multiple risk behaviours, including sexual risk behaviour, violence related activities, poor mental health and substance use. In a systematic review, including interventions for dating and intimate partner violence among young persons (15-30 years), Jennings et al. [24] found that "when considered as a whole, the interventions tended mainly to have a mixed impact with respect to reducing dating/intimate partner violence between treatment and control groups, with most evidence pointing toward promising short-term effects that decayed over time.".

\section{Study limitations}

The study survey was limited to a cross-sectional design, participants attending university and most of the questionnaire administered was by self-report. The questionnaire administered was by self-report, and therefore some of the responses may have been biased; especially sexual risk behaviours and physical IPV and sexual violence victimization among both males and females, may have been underreported. The survey data were limited to cross-sectional. For example, it remains unclear what mechanism or chronology was involved in relation to physical IPV and/or sexual violence victimization and pregnancy, e.g., if physical IPV victimization led to the inability to use condoms, if the abusive partner actively prevented contraception use or if the abused feared using condoms. The study only assessed physical IPV and sexual violence victimization with yes/no response options and did not measure the frequency and severity of victimization, which should be included in future studies with more comprehensive measures. For some variables the confidence intervals were large, e.g. for having been diagnosed with HIV and for some types sexual risk behaviour in students from South Asia and China. This is a further limitation to the interpretation of these specific results, probably due to the low occurrence of the risk behaviour.

\section{Conclusion}

This investigation added evidence for a large university population from 25 countries that physical IPV and/or sexual violence victimization was among male and/or female students associated with 4 of 5 sexual risk behaviours (multiple sexual partners, alcohol use in the context of sex, diagnosed with HIV and pregnancy), 2 violence related behaviours (been in a physical fight and carrying a weapon), 5 of 5 poor mental health indicators (depression, loneliness, PTSD, sleeping problem and 
short sleep), 3 of 3 addictive behaviours (binge drinking, tobacco and drug use) and 2 of 7 other health risk behaviours (skipping breakfast and frequent salt intake). Interventions to prevent physical IPV and sexual violence victimization in this population may include multiple levels, including university- and community-based interventions.

\section{Abbreviations}

IPV: Intimate partner violence; IPAQ: International physical activity questionnaire (IPAQ); PTSD: Posttraumatic stress disorder

\section{Acknowledgements}

Not applicable.

\section{Authors' contributions}

All authors fulfill the criteria for authorship. SP and KP conceived and designed the research, performed statistical analysis, drafted the manuscript and made critical revision of the manuscript for key intellectual content. All authors read and approved the final version of the manuscript and have agreed to authorship and order of authorship for this manuscript.

\section{Funding}

Partial funding for this study was provided by the South African Department of Higher Education. The funder did not play any role in the outcome of this paper.

\section{Availability of data and materials}

The data for the current study will not be shared publicly as participants were informed at the time of providing consent that only researchers involved in the project would have access to the information they provided.

\section{Ethics approval and consent to participate}

The study was conducted in accordance with the Declaration of Helsinki. Participating students signed informed consent forms, and all implementing institutions obtained ethics approvals: Bahria University Medical and Dental College, Cairo University, Chinese University of Hong Kong, Ethics Committee of the University of Yaoundé, National University of Singapore Institutional Review Board, Universidad de Pamplona Ethics Committee, St. George's University Institutional Review Board, Ethics Committee of Institute of Technology and Institute of Sciences at GITAM (Gandhi Institute of Technology and Management) University, Félix Houphouët Boigny University Ethics Committee, University of the West Indies Ethics Committee, Kyrgyz State Medical Academy Ethics Committee, The Ethics Committee of the University of Health Sciences, Ethics Committee of the University of Antananarivo, University of Mauritius Research Ethics Committee, Research Ethics Committee of the University of Namibia, Ethics Review Committee Obafemi Awolowo University, Committee of theWestern Visayas Health Research, Ethics Committee of the Peoples' Friendship University of Russia, Medunsa Research and Ethics Committee (MREC/H/275/2012), Committee for Research Ethics (Social Sciences) of Mahidol University (MU-SSIRB 2015/ 116(B2), National Ethics Committee for Health Research at Institut National de la Santé Publique, Ethics Committee Istanbul University, and Ethics Committee of the Universidad Central de Venezuela.

\section{Consent for publication}

Not applicable.

\section{Competing interests}

The authors declare that they have no competing interests.

\section{Author details}

${ }^{1}$ ASEAN Institute for Health Development, Mahidol University, Salaya, Phutthamonthon, Nakhon Pathom, Thailand. 'Department of Research Administration and Development, University of Limpopo, Turfloop, South Africa. ${ }^{3}$ Department of Psychology, University of the Free State, Bloemfontein, South Africa.
Received: 18 December 2019 Accepted: 5 June 2020

Published online: 02 July 2020

\section{References}

1. Stark L, Seff I, Hoover A, Gordon R, Ligiero D, Massetti G. Sex and age effects in past-year experiences of violence amongst adolescents in five countries. PLoS One. 2019;14(7):e0219073. https://doi.org/10.1371/journal.pone. 0219073 eCollection 2019.

2. Vagi KJ, O'Malley Olsen E, Basile KC, Vivolo-Kantor AM. Teen dating violence (physical and sexual) among US high school students: findings from the 2013 National Youth Risk Behavior Survey. JAMA Pediatr. 2015;169(5):474-82. https://doi.org/10.1001/jamapediatrics.2014.3577.

3. Alleyne B, Coleman-Cowger VH, Crown L, Gibbons MA, Vines LN. The effects of dating violence, substance use and risky sexual behavior among a diverse sample of Illinois youth. J Adolesc. 2011;34(1):11-8. https://doi.org/ 10.1016/j.adolescence.2010.03.006.

4. Blom H, Högberg U, Olofsson N, Danielsson I. Multiple violence victimisation associated with sexual ill health and sexual risk behaviours in Swedish youth. Eur J Contracept Reprod Health Care. 2016;21(1):49-56. https://doi. org/10.3109/13625187.2015.1089227.

5. World Health Organization (WHO). Understanding and addressing violence against women intimate partner violence: Intimate partner violence, 2012. URL: https://apps.who.int/iris/bitstream/handle/10665/77432/WHO_ RHR_12.36_eng.pdf;jsessionid=A2FDCCF3D7D1E79A00E23B1C9673C6 $0 A$ ? sequence $=1$. Accessed 10 Nov 2019

6. Silverman JG, Raj A, Mucci LA, Hathaway JE. Dating violence against adolescent girls and associated substance use, unhealthy weight control, sexual risk behavior, pregnancy, and suicidality. JAMA. 2001;286(5):572-9.

7. Silverman JG, Raj A, Clements K. Dating violence and associated sexual risk and pregnancy among adolescent girls in the United States. Pediatrics. 2004;114(2):e220-5

8. Nguyen $\mathrm{KH}$, Padilla M, Villaveces A, Patel P, Atuchukwu V, Onotu D, Apondi R, Aluzimbi G, Chipimo P, Kancheya N, Kress H. Coerced and forced sexual initiation and its association with negative health outcomes among youth: results from the Nigeria, Uganda, and Zambia violence against children surveys. Child Abuse Negl. 2019;96:104074. https://doi.org/10.1016/j.chiabu. 2019.104074.

9. Taquette SR, Monteiro DLM. Causes and consequences of adolescent dating violence: a systematic review. J Inj Violence Res. 2019:11(2):137-47. https:// doi.org/10.5249/jivr.v11i2.1061.

10. Brewer NQ, Thomas KA. Intimate partner violence and academic performance: the role of physical, mental, behavioral, and financial health. Soc Work Health Care. 2019;58(9):854-69. https://doi.org/10.1080/00981389.2019.1659905.

11. Campbell JC. Health consequences of intimate partner violence. Lancet. 2002;359(9314):1331-6.

12. Dillon G, Hussain R, Loxton D, Rahman S. Mental and physical health and intimate partner violence against women: a review of the literature. Int J Family Med. 2013;2013:313909. https://doi.org/10.1155/2013/313909.

13. Reza A, Breiding MJ, Gulaid J, Mercy JA, Blanton C, Mthethwa Z, Bamrah S, Dahlberg LL, Anderson M. Sexual violence and its health consequences for female children in Swaziland: a cluster survey study. Lancet. 2009;373(9679): 1966-72. https://doi.org/10.1016/S0140-6736(09)60247-6.

14. Basile KC, Black MC, Simon TR, Arias I, Brener ND, Saltzman LE. The association between self-reported lifetime history of forced sexual intercourse and recent health-risk behaviors: findings from the 2003 National Youth Risk Behavior Survey. J Adolesc Health. 2006;39(5):752.e1752.e7527. https://doi.org/10.1016/j.jadohealth.2006.06.001.

15. Mathew AE, Marsh B, Smith LS, Houry D. Association between intimate partner violence and health behaviors of female emergency department patients. West J Emerg Med. 2012;13(3):278-82. https://doi.org/10.5811/ westjem.2012.3.11747.

16. Lagdon S, Armour C, Stringer M. Adult experience of mental health outcomes as a result of intimate partner violence victimisation: a systematic review. Eur J Psychotraumatol. 2014;5. https://doi.org/10.3402/ejpt.v5.24794 eCollection 2014.

17. Randle AA, Graham CA. A review of the evidence on the effects of intimate partner violence on men. Psychol Men Masc. 2011;12(2):97-111. https://doi. org/10.1037/a0021944

18. Wood L, Voth Schrag R. Busch-Armendariz N mental health and academic impacts of intimate partner violence among IHE-attending 
women. J Am Coll Heal. 2018;17:1-8. https://doi.org/10.1080/07448481. 2018.1546710.

19. Wong JYH, Choi EPH, Lo HHM, Wong W, Chio JHM, Choi AWM, Fong DYT. Intimate partner sexual violence and mental health indicators among Chinese emerging adults. J Interpers Violence. 2019;886260519872985. https://doi.org/10.1177/0886260519872985.

20. Banyard VL, Cross C. Consequences of teen dating violence: understanding intervening variables in ecological context. Violence Against Women. 2008; 14(9):998-1013. https://doi.org/10.1177/1077801208322058.

21. Martín-Baena D, Talavera M, Montero-Piñar I. Interpersonal violence and health in female university students in Spain. J Nurs Scholarsh. 2016;48(6): 561-8. https://doi.org/10.1111/jnu.12239.

22. Pengpid S, Peltzer K. Lifetime spousal violence victimization and perpetration, physical illness, and health risk behaviours among women in India. Int J Environ Res Public Health. 2018;15(12). https://doi.org/10.3390/ ijerph15122737.

23. Sanz-Barbero B, Barón N, Vives-Cases C. Prevalence, associated factors and health impact of intimate partner violence against women in different life stages. PLoS One. 2019;14(10):e0221049. https://doi.org/10.1371/journal. pone.0221049 eCollection 2019.

24. Jennings WG, Okeem C, Piquero AR, Sellers CS, Theobald D, Farrington DP. Dating and intimate partner violence among young persons ages 15-30: evidence from a systematic review. Aggress Violent Behav. 2017. https://doi. org/10.1016/j.avb.2017.01.00.

25. James C, Powell M, Seixas A, Bateman A, Pengpid S, Peltzer K. Exploring the psychometric properties of the CES-D-10 and its practicality in detecting depressive symptomatology in 27 low- and middle-income countries. Int J Psychol. 2019. https://doi.org/10.1002/ijop.12613.

26. Pengpid S, Peltzer K. Correlates of sedentary behaviour among university students with depression from 22 low- and middle-income countries. J Hum Behav Soc Environ. 2019;29(7):833-9. https://doi.org/10.1080/10911359. 2019.1610134

27. Peltzer K, Pengpid S, Yung TK, Aounallah-Skhiri H, Rehman R. Comparison of health risk behavior, awareness, and health benefit beliefs of health science and non-health science students: an international study. Nurs Health Sci. 2016;18(2):180-7. https://doi.org/10.1111/nhs.12242.

28. Straus MA, Hamby SL, Boney-McCoy S, Sugarman DB. The revised conflict tactics scales (CTS2) - development and preliminary psychometric data. J Fam Issu. 1996;17:283-316.

29. Brock D, Sarason I, Sarason B, Pierce G. Simultaneous assessment of perceived global and relationship-specific support. J Soc Pers Relatsh. 1996; 13:143-52.

30. Richter L, Komárek A, Desmond C, Celentano D, Morin S, Sweat M, Chariyalertsak S, Chingono A, Gray G, Mbwambo J, Coates T. Reported physical and sexual abuse in childhood and adult HIV risk behaviour in three African countries: findings from project accept (HPTN-043). AIDS Behav. 2014;18(2):381-9. https://doi.org/10.1007/s10461-013-0439-7.

31. Peltzer K. Pengpid S mental health correlates of HIV risk behaviour and STIS/ HIV infection among university students from 22 low, middle and high income countries. J Psychol Afr. 2015;25(2):121-6.

32. Centers for Disease Control (CDC). Questionnaire - CDC Global Schoolbased Student Health Survey, 2013. Retrieved from www.cdc.gov/gshs/ questionnaire/index.htm, Accessed 10 Oct 2018.

33. Youth Risk Behavior Survey (YRBS) (2011). Youth risk behavior survey. URL: http// unw.imnashville .com/home/youth-violence/surveillance-data/youth-risk-behaviorsurvey-yrbs-us-tn-nashvilledavidsoncounty/. Accessed 10 Nov 2019.

34. Andresen EM, Malmgren JA, Carter WB, Patrick DL. Screening for depression in well older adults: evaluation of a short form of the CES-D (Center for Epidemiologic Studies Depression Scale). Am J Prev Med. 1994;10:77-84.

35. Breslau N, Peterson EL, Kessler RC, Schultz LR. Short screening scale for DSM-IV posttraumatic stress disorder. Am J Psychiatry. 1999;156:908-11.

36. Peltzer K, Pengpid S. Sleep duration and health correlates among university students in 26 countries. Psychol Health Med. 2016;21 (2):208-20. https://doi. org/10.1080/13548506.2014.998687.

37. Peltzer K, Pengpid S. Nocturnal sleep problems among university students from 26 countries. Sleep Breath. 2015;19(2):499-508. https://doi.org/10.1007/ s11325-014-1036-3.

38. Bush K, Kivlahan DR, McDonell MB, Fihn SD, Bradley KA. The AUDIT alcohol consumption questions (AUDIT-C): an effective brief screening test for problem drinking. Ambulatory care quality improvement project (ACQUIP).
Alcohol use disorders identification test. Arch Intern Med. 1998;158(16): 1789-95. https://doi.org/10.1001/archinte.158.16.1789.

39. World Health Organization (WHO). Guidelines for Controlling and Monitoring the Tobacco Epidemic. Geneva: WHO; 1998.

40. Yi S, Peltzer K, Pengpid S, Susilowati IH. Prevalence and associated factors of illicit drug use among university students in the association of southeast Asian nations (ASEAN). Subst Abuse Treat Prev Policy. 2017;12(1):9. https:// doi.org/10.1186/s13011-017-0096-3.

41. Craig CL, Marshall AL, Sjöström M, Bauman AE, Booth ML, Ainsworth BE, Pratt M, Ekelund U, Yngve A, Sallis JF, Oja P. International physical activity questionnaire: 12-country reliability and validity. Med Sci Sports Exerc. 2003; 35(8):1381-95. https://doi.org/10.1249/01.MSS.0000078924.61453.FB.

42. International Physical Activity Questionnaire (IPAQ) Research Committee International Physical Activity Questionnaire. 2016. Available online: https:// sites.google.com/site/theipaq/scoring-protocol. Accessed 20 Oct 2018.

43. Wardle J, Steptoe A. The European health and behaviour survey: rationale, methods and initial results from the United Kingdom. Soc Sci Med. 1991;33: 925-36.

44. Hall JN, Moore S, Harper SB, Lynch JW. Global variability in fruit and vegetable consumption. Am J Prev Med. 2009;36(5):402-409.e5. https://doi. org/10.1016/j.amepre.2009.01.029.

45. World Health Organization (WHO). Diet, nutrition and the prevention of chronic diseases: Report of a Joint WHO/FAO Expert Consultation. Geneva: WHO; 2003

46. Peltzer K, Pengpid S. Health behaviour and self-reported academic performance among university students: an international study. MJSS. 2014 5(27):998-1005. https://doi.org/10.5901/mjss.2014.v5n27p998.

47. Herman JL. Complex PTSD: A syndrome in survivors of prolonged and repeated trauma. J Trauma Stress. 1992;5:377-91.

48. Van Der Kolk BA. Psychological trauma. Washington, DC: American Psychiatric Publishing; 2003.

49. Exner-Cortens D, Eckenrode J, Rothman E. Longitudinal associations between teen dating violence victimization and adverse health outcomes Pediatrics. 2013;131(1):71-8. https://doi.org/10.1542/peds.2012-1029.

50. Lazarus RS, Folkman S. Stress, appraisal, and coping. New York: Springer Publishing Company; 1984.

\section{Publisher's Note}

Springer Nature remains neutral with regard to jurisdictional claims in published maps and institutional affiliations.
Ready to submit your research? Choose BMC and benefit from:

- fast, convenient online submission

- thorough peer review by experienced researchers in your field

- rapid publication on acceptance

- support for research data, including large and complex data types

- gold Open Access which fosters wider collaboration and increased citations

- maximum visibility for your research: over $100 \mathrm{M}$ website views per year

At BMC, research is always in progress.

Learn more biomedcentral.com/submissions 